\title{
Effect of Stress-response Psycho-training on the Stress Levels of Mothers with Autistic Children*
}

\author{
Ömer Karaman \\ Department of Guidance and Counseling, Faculty of Education, Ordu University, Turkey
}

Copyright $\bigcirc 2018$ by authors, all rights reserved. Authors agree that this article remains permanently open access under the terms of the Creative Commons Attribution License 4.0 International License

\begin{abstract}
The aim of the study was to assess the effect of stress-response psycho-training on the stress levels of mothers with autistic children. The research was experimental in design encompassing a pretest-posttest model with control and placebo groups. Participation in the study was voluntary with a total of 28 mothers of autistic children included with 10 in the experimental group, 11 in the control group and 7 in the placebo group. The Perceived Stress Scale was used as the data collection tool in the research. Stress-response psycho-training based on the cognitive-behavioral approach developed by the researcher was applied with the aim of lowering stress levels of participants in the experimental group over 9 weekly sessions. The placebo group participated in 3 sessions of group guidance activities about the causes of stress and place in life. The control group did not have any procedures applied. For statistical analysis the repeated measurements variance analysis technique was used. The stress-response psycho-training applied in the research was identified to have a significant effect in reducing the stress levels of mothers with autistic children. The obtained results are discussed within the framework of other research in the relevant literature and recommendations are made.
\end{abstract}

\section{Keywords Autism, Stress, Psycho-training}

\section{Introduction}

The disability group of autism is a common developmental disorder beginning before the age of 3 years and continuing through life, with delays and/or deviations in social relationships, behavior and cognitive development. Autism was associated with negative parental attitudes and absence of love in the 1940s. Though the reason for autism is not fully known, factors may be listed including psychosocial experiences, prenatal and antenatal problems, neurobiological factors and genetic disposition [1]. The incidence of autism has been identified as $1 / 88$ [2]. According to gender, the incidence in males is 4 times the rate in females [3]. However, the incidence in mentally disabled individuals is reported to rise up to $21 \%$ [4]. In children with autism diagnosis, mental retardation is identified in $70 \%$ [5]. In addition to the mental retardation observed in autism, it may be observed with epileptic disorders, gastrointestinal, immunologic and non-specific neurologic disorders [5].

As autism affects the development of the child in communication, emotional, cognitive, social and behavioral areas, it may cause more problems for families compared to other disabilities [6]. Of autistic cases, 2/3 live dependent or semi-dependent lives due to loss of competence and only 1-2\% live independently with 5-10\% living at the border of dependence [7].

Having a disabled child is a long and difficult process for parents where periods of shock, disbelief, grief, focus and acceptance are experienced. In this period factors like the abstraction from social life, worries about the future, and living with a dependent child are significant factors causing stress and depression in families [8]. Additionally, the treatment and education for autism is very difficult and problematic which may exponentially increase the stress levels in families. As a result, family support studies are important. Studies have determined that continuous dependence of the child, requirements for special care and worries about the future are stress factors in families with disabled children. Additionally, cognitive disorders, life limitations, family incompatibility and additional economic loads may be shown as causes of stress $[9,10]$. Another variable affecting the stress levels of parents is helplessness and hopelessness linked to other factors experienced caused by the disabled child. In this way, parents of disabled children may experience emotional problems like life satisfaction, continuous and situational anxiety levels along with intense stress disorders. Significant stress factors include the social communication insufficiency and unpredictable impulsive, aggressive and hyperactive attitudes of autistic children, in addition to the process of maintaining family order, dealing with unusual behavior, continuous need for supervision, personal 
requirements and dealing with other family problems [11].

Currently cognitive-behavioral techniques are commonly used in psycho-training group applications. Psycho-training benefits from group dynamics within the process of developing the life skills and dealing with the problems of individuals and is pioneering in that it is open to participants of all ages. In this study, psycho-training was designed and applied to a group in accordance with the cognitive-behavioral school.

The aim of the research was to study the effect of stress-response psycho-training applications on the stress levels of mothers of autistic children.

\section{Materials and Methods}

The method was experimental based on the pretest-posttest model of experimental, control and placebo groups. The study included a total of 28 mothers of autistic children, with stress levels above average, with 10 in the experimental, 7 in the control and 11 in the placebo group. The data collection tool in the research was the Perceived Stress Scale. With the aim of lowering the stress levels in the experimental group, a stress-response psycho-training developed by the researcher based on the cognitive-behavioral therapy approach was applied. The placebo group had 3 sessions of group guidance activity about the causes of stress and its place in life, while the control group did not have any application performed. For statistical analysis the two-factor ANOVA (SPANOVA) for mixed patterns technique was used.

Participants in the research were parents of autistic students under the supervision of Altinordu Guidance and Research Center Directorate linked to Ordu Provincial National Education Directorate. The process of the study was explained and groups were formed on a voluntary basis.

The Perceived Stress Scale (PSS) developed by Cohen et al. [12] and adapted to Turkish by Eskin et al. [13] was used as the data collection tool. The internal consistency coefficient of the Turkish adaptation of the PSS was 0.84, with test-repeat test reliability coefficient of 0.87 .

The PSS comprises a total of 14 items and has an assessment structure based on a 5-point Likert type from "Never (0)" to "Always (4)". Seven of the items are positive statements and are given inverse points. As points increase, stress is assessed as increasing.

\subsection{Psycho-training Application Process}

The aim of the stress-response psycho-training application was to develop the individual's skills in dealing with stress. In this way, group sessions were structured on a cognitive-behavioral basis. Each session lasted 50 minutes, with 9 sessions planned. In the first session, the aims and rules of the group were stated and an introduction activity was completed. In the second session, explanations were made about the definition of stress and the emotional, intellectual, behavioral and physical signs. In line with this, the "Stress Factor Determination Form" developed by the researcher was given as homework to determine stress factors in the participants' lives. In the third session, in line with the data obtained by the group members in the homework, the group worked on experiences causing stress. In the fourth session, automatic thoughts and results developed against stress by group members were assessed. In the fifth session, stress-response methods were worked on and homework to be completed daily was given. In the sixth session, the homework was discussed and members were requested to develop and apply new strategies. In the seventh session, studies were completed where group members clarified for themselves behavioral patterns indicating strategies that worked and did not work. In the eighth session, group members assessed the stress-response methods they had designed. In the final ninth session, a general summary of the sessions was given. Group members described changes in themselves during the process and shared their feelings at the end of the session.

\section{Result}

To test whether there was a difference in mean pretest points for parents of autistic students in the experimental, control and placebo groups before psycho-training group studies, the repeated measures variance analysis was performed using the SPSS $20.0 \mathrm{~V}$ program. As a result of statistical processes performed on the points obtained from the scale in the groups, the distribution was identified as normal and the variance was homogeneous.

According to variance analysis of pretest measurements of the Perceived Stress Scale in the experimental, control and placebo groups, there was no significant difference between the pretest points in the experimental, control and placebo groups $(\mathrm{F}(2.25)=1.19, \mathrm{p}>0.05)$. The experimental, control and placebo groups did not differ in terms of mean pretest points on the Perceived Stress Scale. Mean score pretest and posttest in experimental, control and placebo groups are given in figure 1 . 


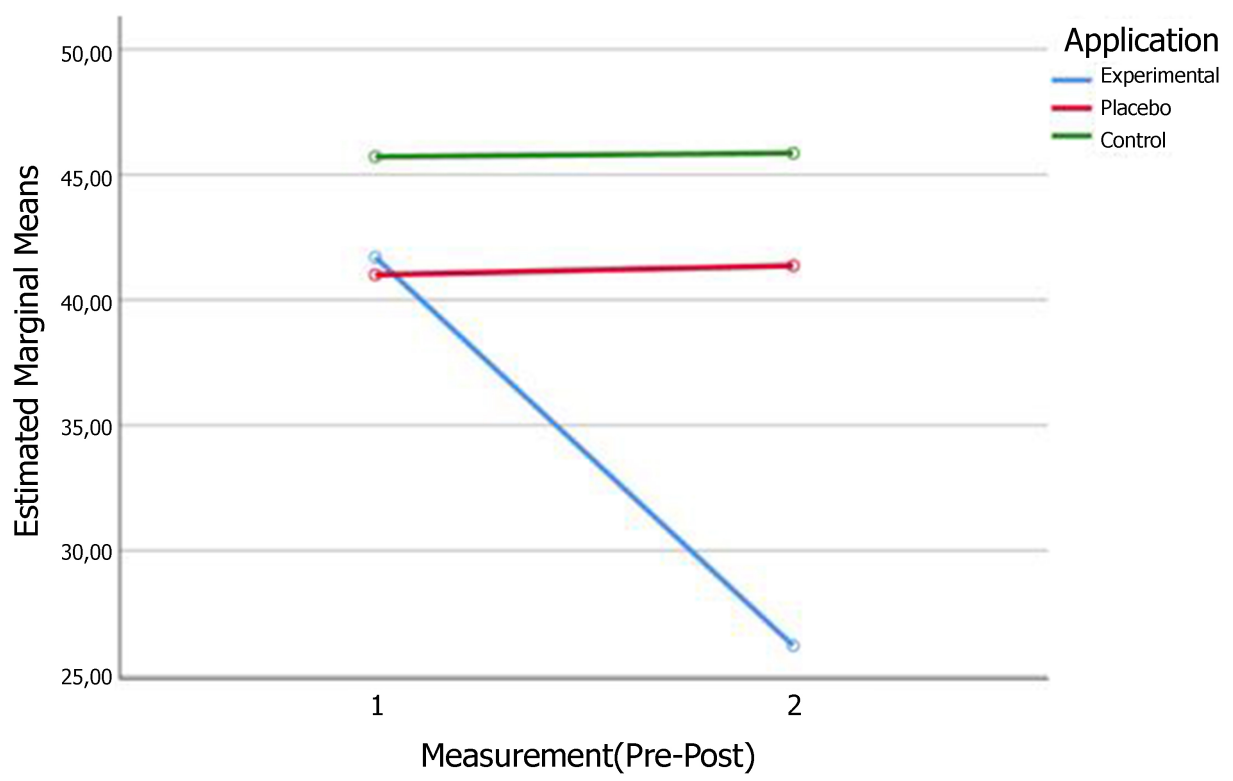

Figure 1. Mean score pretest and posttest in experimental, control and placebo groups.

The mean points and standard deviation values for Perceived Stress Scale pretest and posttest in experimental, control and placebo groups are given in Table 1 .

Table 1. Mean points and standard deviation for Perceived Stress Scale pretest and posttest in experimental, control and placebo groups

\begin{tabular}{|c|c|c|c|c|}
\hline \multicolumn{5}{|c|}{ Descriptive Statistics } \\
\hline Application & Mean & Std. Deviation & $\mathrm{N}$ & $P$ value \\
\hline Pretest Experimental & 41.7000 & 6.92901 & 10 & \multirow{2}{*}{0.005} \\
\hline Post Experimental & 26.2000 & 8.28385 & 10 & \\
\hline Pretest Placebo & 41.0000 & 7.09930 & 11 & \multirow{2}{*}{0.477} \\
\hline Posttest Placebo & 41.3636 & 6.87419 & 11 & \\
\hline Pretest Control & 45.7143 & 4.85504 & 7 & \multirow{2}{*}{0.705} \\
\hline Post Control & 45.8571 & 4.63424 & 7 & \\
\hline Pretest Total & 42.4286 & 6.61328 & 28 & \multirow{2}{*}{0.012} \\
\hline Post Total & 6.61328 & 10.79070 & 28 & \\
\hline
\end{tabular}

As seen in Table 1, the mean posttest points $(X=26.20)$ for the experimental group on the Perceived Stress Scale had fallen compared to the mean pretest points $(\mathrm{X}=$ 41.70). In the placebo group, the mean posttest points (X $=41.36)$ were similar to the mean pretest points $(\mathrm{X}=$ 41.00). Again in the control group, there was no significant difference found between the mean posttest points $(\mathrm{X}=45.85)$ and the mean pretest points $(\mathrm{X}=$ 45.71).

The comparisons between the mean points obtained by the experimental, control and placebo groups and between pretest and posttest measurement values were analyzed with the ANOVA (SPANOVA). The variance analysis results related to the pretest and posttest measurements of the Perceived Stress Scale in the experimental, control and placebo groups are given in Table 2.

Table 2. Variance analysis results for Perceived Stress Scale pretest and posttest points

\begin{tabular}{|c|c|c|c|c|c|}
\hline Source of Variance & KT & SD & KO & F & P \\
\hline Between subjects & 3423.500 & 27 & 126.7962963 & & \\
\hline Group & 1227.920 & 2 & 613.960 & 6.991 & 0.004 \\
\hline Error & 2195.580 & 25 & 87.823 & & \\
\hline Within subjects & 1237.985 & 28 & 44.214 & & \\
\hline $\begin{array}{c}\text { Measurement } \\
\text { (pretest-posttest) }\end{array}$ & 336.770 & 1 & 336.770 & 83.399 & $<0.001$ \\
\hline $\begin{array}{c}\text { Measurement } \\
* \text { Group }\end{array}$ & 800.263 & 2 & 400.131 & 99.090 & $<0.001$ \\
\hline Error & 100.951 & 25 & 4.038 & & \\
\hline Total & 4661.485 & 55 & & & \\
\hline
\end{tabular}

As observed in Table 2, the basic effect of the Perceived Stress Scale pretest was found to be significant in the experimental, control and placebo groups (F (1.25) $=83.339, \mathrm{p}<0.05)$. The mean points for individual thoughts in the experimental, control and placebo groups and the measurement $\mathrm{x}$ group common effect were significant $(F(2.25)=99.090, p<0.05)$. Again, there was a significant difference identified between the Perceived Stress Scale mean points $(\mathrm{F}(2.25)=6.991, \mathrm{p}<0.05)$ in the experimental, control and placebo groups.

Significant differences were identified in terms of the stress measurements between the groups in the study. After the stress measurement applications, there was a linear reduction in the control, placebo and experimental 
groups. In the experimental group there was a more severe reduction in stress measurements compared to the other groups (placebo and control).

The data obtained show that according to pretest results, all of the experimental, control and placebo groups had high levels of perceived stress. Similarly, many studies have identified that families with autistic children have higher stress levels compared to families with other types of disabled children [10].

According to posttest results completed after the psycho-training application, the perceived stress levels in the experimental group significantly fell compared to the control and placebo groups.

\section{Discussion and Conclusions}

In this study the psycho-training application for mothers of autistic children was identified to significantly reduce stress levels. Similarly, a coping skills development program applied by Gammon and Rose [14] was determined to significantly reduce the stress levels in families with children with developmental retardation. In addition, it was stated that psycho-educational group guidance activities for families with any type of disabled child reduce anxiety and emotional pain, in addition to lowering stress levels $[10,15]$. Another study identified that psycho-educational counseling reduced depression in families with autistic children and increased self-esteem. Differently, Aksaz [16] investigated the effect of information counseling applications on the anxiety levels of mothers and fathers of autistic children and found no significant difference between the control and experimental groups. Erguner-Tekinalp and Akkok [17] applied a coping skills program for mothers of autistic children and identified that the stress levels of mothers did not change after the application.

The study was completed as a cognitive-behavioral therapy-based psycho-training group application. Cognitive-behavioral therapy includes work related to individuals noticing non-functional thoughts and beliefs and discovering how to change them [18]. The psycho-training group applications focused on thoughts developed against stress by group members. After a short duration of group sessions, members became aware of automatic thoughts and were observed to develop alternative thoughts together with the group dynamics. Later strategy was followed in line with including these thoughts in life and the focus on the experience of using these thoughts in life played an effective role in reducing stress. In the study homework had great importance, because in cognitive-behavioral therapy homework is effective in the client gaining courage to overcome the problem, learning new behavioral skills and making them permanent $[19,20]$. Important factors in the psycho-training group achieving their aims were the enthusiastic completion of homework by clients and participants paying maximum attention in group sessions. To increase participation of clients in group sessions, group sessions were held in the school for autistic children forming the population of the study and session hours were held close to the end of the school day. After sessions the clients went home with their children. The clients enthusiastically completing the homework may be due to the needs of the mothers of disabled children. Studies of mothers of disabled children have determined requirements for training and professional aid with social support by mothers especially [21, 22].

According to the data obtained, it is concluded that the application of stress-related psycho-training studies should be increased for mothers of autistic children. It is necessary to develop strategies for fathers to participate in these types of studies. The data of the psychological counseling service responsible for autistic children was effective in the lack of inclusion of fathers. According to this, all educational monitoring and aid for autistic children was organized by the mother and the fathers did not provide necessary support. As a result it was considered a reality that mothers experienced stress more intensely. The fact that mothers of children with disabled children experience more stress compared to fathers may be linked to the cultural maternal roles [23]. Mothers are alone in taking responsibility for disabled children [24, 25].

Information collected from mothers during training in the placebo group and in the psycho-training process was assessed. Accordingly, it is recommended that effective family monitoring be completed by social services immediately after autism diagnosis, that family training and individual education for the autistic child begin as soon as possible, that material and technical equipment for education be provided and for families' social activities, foundations and introductory activities for families with autistic children be completed.

\section{REFERENCES}

[1] Turkoglu S, Bilgic A, Uslu R. Trizygotic Triplets with Autistic Spectrum Disorders: Case Report and Literature Review). Arc hi Ves of Neu Ropsy Chi Atry 49: 167-171, 2012.

[2] Sabuncuoglu M, Cebeci S, Rahbar Mh, Hessabi M. Autism Spectrum Disorder and Attention Deficit Hyperactivity Disorder: Knowledge and Attitude of Family Medicine Residents in Turkey. Turkish Journal of Family Medicine \& Primary Care 9 (2):46-53, 2015

[3] Lord C and Bishop SL. Social Policy Report. Autism Spectrum Disorders: Diagnosis, Prevalence, and Services for Children and Families. Sharing Child and Youth Development Knowledge 24(2):1-27, 2010 
[4] Gormez A, Kirpinar I. Autism Spectrum Disorders: Changes and Psychiatric Comorbidities in Adulthood. New Symposium 53(4): 27-33, 2015

[5] Sener EF, Ozkul Y. The Genetic Basis of Autism. Journal of Health Sciences. 22(1): 86-92, 2013

[6] Meral BF, Cavkaytar A. The Perceptions of Family Quality of Life of Parents of Children with Autism. K. U. Kastamonu Education Journal 23 (3), 1363-1380, 2015

[7] Dogangün B. Psychiatric Situations with Special Education. Common Psychiatric Disorders Symposium in Turkey. No: 62:157-174. İ.Ü. Cerrahpasa Medical School Continuous Medical Education Activities, 2008

[8] Yuksel M Y, Eren B S. Examination of the effect of group counselling on the level of depression and problem solving skills of the mothers whose children are autism, Journal of Educational Sciences 25 (25); 197-210, 2007

[9] Kucuker S. Examining the Effects of an Early Intervention Developmental Delays on Then Parent's Stress and Depression Levels. Ankara University Faculty of Educational Sciences Journal of Special Education 3 (1): $1-11,2001$

[10] Vardarci G. The effects of a parent training program to the parents of children with autism on their interpersonal relationship skills, problem solving skills and their perceptions about their children with autism. Dokuz Eylül University, Graduate School of Educational Sciences Graduate Thesis, İzmir, 2011

[11] Firat S. Levels of depression and anxiety among parents of autistic children. Cukurova Med J 41(3):539-547, 2016

[12] Cohen S, Kamarck T, Mermelstein R. A global measure of perceived stress. Journal of Health and Social Behavior; 24: $385-396,1983$

[13] Eskin M, Harlak H, Demirkiran F, Dereboy Ç. The Adaptation of the Perceived Stress Scale into Turkish: A Reliability and Validity Analysis. New Symposium Journal 51(3): 132-140, 2013

[14] Gammon EA ve Rose SD. The Coping Skills Training Program for parents of children with developmental disabilities: An experimental evaluation. Research on Social Work Practice 1(3): 244-256, 1991

[15] Piskin U, Gumuscu Ş. A case report from a short-term educational program of an autistic child and his family. Turk Psikoloji Derg, 9(32):30-34, 1994

[16] Aksaz, K.N. The Impact of Informing Counseling on Anxiety Levels of Parents with Autistic Children. Ankara University Ankara University Social Sciences Institute Graduate Thesis, Ankara, 1992

[17] Ergunel-Tekinalp, B. and Akkok, F.The effects of a coping skills training program on the coping skills, hopelessness, and stress levels of mothers of children with autism. International Journal for the Advancement of Counselling 26(3): 257-269, 2004

[18] Corey, G. Psikolojik danışma, psikoterapi kuram ve uygulamaları. (Çev: T. Ergene). Ankara: Mentis Yayıncılık. 2005

[19] Haarhoff, B. A. \& Kazantzis, N. How to supervise the use of homework in cognitive behavior therapy: The role of trainee therapist beliefs. Cognitive and Behavioral Practice, 14(3): $325-332,2007$

[20] Rees, C. S., McEvoy, P. \& Nathan, P. R. Relationship between homework completion and outcome in cognitive behaviour therapy. Cognitive Behaviour Therapy, 34(4): 242-247, 2005

[21] Ergin D, Sen N, Eryilmaz N, Pekuslu S, Kayac1 M, Level of Depression of Parents with Handicapped Children and Determination of the Affecting Factors. Atatürk U Hem Yük Derg, 10(1): 41-48, 2007

[22] Koksal G. Examination of factors predicting the perceived stress of parents with mentally retarded children. Dokuz Eylül University Ankara University Education Sciences Institute Graduate Thesis, İzmir, 2011

[23] Duygun T, Sezgin N. The Effects of Stress Symptoms, Coping Styles and Perceived Social Support on Burnout Level of Mentally Handicapped and Healthy Children's Mother. Turk Psikoloji Derg, 18(52): 37-52, 2003

[24] Kazak, A. E., \& Marvin, R. S. Differences, difficulties and adaptation: Stress and social networks in families with a handicapped child. Family Relations, 33: 67-77, 1984

[25] Taanila, A., Jarvelin, M. R., \& Kokkonen, J. Cohesion and parents' social relations in families with a child with disability or chronic illness. International Journal of Rehabilitation Research, 22, 101-109, 1999 